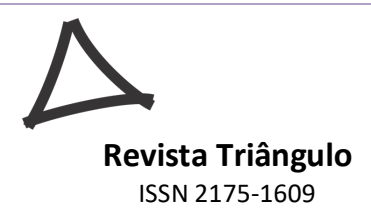

\title{
O LIVRO DIDÁTICO COMO DOCUMENTO HISTÓRICO PARA ANÁLISE DO CURRÍCULO DE QUÍMICA E CIÊNCIAS
}

\author{
THE TEXTBOOK AS A HISTORICAL DOCUMENT FOR ANALYZING THE CHEMISTRY \\ CURRICULUM AND SCIENCES
}

\author{
EL LIBRO DIDÁCTICO COMO DOCUMENTO HISTÓRICO PARA ANÁLISIS DEL \\ CURRÍCULO DE QUÍMICA Y CIENCIAS
}

Francisco de Araújo Silva Instituto Federal de Educação, Ciência e Tecnologia de São Paulo (IFSP) E-mail: francisco@,ifsp.edu.br

\author{
Jacqueline Querino Alves \\ Prefeitura Municipal de Ribeirão Preto. E-mail: jacqueline.querino.alves@gmail.com \\ Joana de Jesus Andrade \\ Universidade de São Paulo (USP). E-mail: joanajandrade@gmail.com
}

\begin{abstract}
RESUMO
Este trabalho apresenta um breve resgate da história dos currículos de ciências e de química no Brasil considerando os aspectos legais bem como cenários sociais mais amplos intervenientes na elaboração de livros didáticos (LD) de ciências, do $9 .^{\circ}$ ano do Ensino Fundamental, e química, do $1^{\circ}$ ano do Ensino Médio. Ao reconhecer a importância dos LDs como 'documentos históricos' da educação e, com inspiração na perspectiva das teorias críticas do currículo, foram analisados seis LDs por meio da análise de conteúdo, a partir das categorias de conteúdo curricular e temas contextuais. A presença, bem como as semelhanças e diferenças, de conteúdos de química e de possíveis contextos de utilização em ambos os níveis de ensino, foram os disparadores da investigação que reconhece, nas categorias definidas, os valores sociais atribuídos ao ensino da Química na educação básica. Concluiu-se que os LDs, embora tentem cumprir o disposto nos documentos orientadores do ensino, apresentam disparidades entre as necessidades sociais mais amplas, as demandas econômicas do país e/ou as perspectivas políticas que as leis e outros documentos expressam. Ficou evidente que os conteúdos curriculares apresentam considerável semelhança em diferentes épocas históricas e que os temas contextuais de utilização/aplicação destes conteúdos seguem as tendências mundiais de ensino contextualizado.
\end{abstract}

PALAVRAS-CHAVE: Livro didático. Currículo de química. Reformas educacionais.

\footnotetext{
ABSTRACT

This paper presents a historical review of science and chemistry curriculum in Brazil considering the legal aspects likewise social scenarios involved in the development of didactic books (DBs) of the ninth year of Elementary School and the first year of High School. Recognizing the importance of DBs as historical documents' of education and inspired by the perspective of the critical theories of the curriculum, henceforth six textbooks were analyzed from the content and themes. The presence, as well as the similarities and differences, of chemical contents and possible contexts of use in both levels of education, were the triggers of research that recognizes, in the defined categories, the social values attributed to the teaching of Chemistry in basic education. It was concluded that DBs however, attempts to comply with the guidance documents present a distinction between broader social needs, economic demands of the country from political perspectives which laws and other documents proclaim. It was evident that the contents have considerable similarity in different historical moments and that contextual themes of use/application of such content succeeding the trends of contextualized teaching.
} 
KEYWORDS: Didactic book. Chemistry curriculum. Education reforms.

\section{RESUMEN}

Este trabajo presenta el rescate del currículo de ciencias y química en Brasil, considerando los aspectos legales, así como escenarios sociales más amplios que intervienen en la elaboración de libros didácticos (LD) de ciencias en el $9^{\circ}$ año de la Educación Primaria y química del $1^{\circ}$ año de la Educación Secundaria. Al reconocer la importancia de los LDs como 'documentos históricos' de la educación y con inspiración en la perspectiva de las teorías críticas del currículo, fueron analizados seis LDs a partir de las categorías de contenido y temas contextuales. La presencia, así como las similitudes y diferencias, de contenidos de química y de posibles contextos de utilización en ambos niveles de enseñanza, fueron los disparadores de la investigación que reconoce, en las categorías definidas, los valores sociales atribuidos a la enseñanza de la Química en la educación básica. Se concluyó que los LDs, aunque intenten cumplir con las disposiciones en los guías de enseñanza, presentan disparidades entre las necesidades sociales más amplias, las demandas económicas del país o las perspectivas politicas que las leyes y otros documentos expresan. Es evidente que los contenidos presentan semejanza considerable en diferentes épocas históricas y que los temas contextuales de utilización/aplicación de estos contenidos siguen las tendencias mundiales de enseñanza contextualizada.

PALABRAS-CLAVE: Libro didáctico. Currículo de química. Reformas educacionales.

\section{INTRODUÇÃO}

A escola, enquanto instituição que organiza, planeja e realiza ações de formação na infância e juventude, guarda na sua estrutura e no seu funcionamento as premissas da responsabilidade de formar/conformar/transformar o ser humano. Tal incumbência é recente na história da humanidade (SAVIANI, 2007) e a escola como espaço de acontecimento dessa intervenção é constantemente alvo de avaliações das mais diversas ordens. Questionam-se as idades (de entrada e saída), os conteúdos programáticos, os objetivos do ensino, o modo de ensinar do professor, a efetividade e qualidade das ações, enfim, as dúvidas e as mudanças (também políticas) mostram vários aspectos, mas principalmente, que estes espaços e processos demandam (ainda) muitas investigações.

No sistema escolar, diversos cenários desenham e identificam as relações humanas com vistas à educação de si e do outro. Dentre os cenários possíveis, um deles, com definição controversa na mesma intensidade de sua importância e presença, é o currículo. As primeiras relações entre educação e currículo são registradas no século XVI através de práticas difundidas em universidades e escolas (GOODSON, 1995; SILVA, 2007). O estudo desta relação ganhou fôlego, teve grande expansão no século XX e continua em foco no século XXI. Atualmente, as definições de currículo não se resumem à imagem estática de expressões como 'grade curricular' ou 'lista de conteúdos', que retratam uma burocracia organizacional e estrutural muitas vezes desconexa de sua atribuição social mais ampla. Das influências estadunidenses do currículo relacionado à organização fabril até às mudanças sociais, culturais e políticas da década de 1960 - que realçaram as teorias críticas do currículo -, o 
papel da escola através do que se ensina tem ocasionado discussões contínuas, não raramente mobilizadas por grandes mudanças nos marcos legais (SILVA, 2007).

Com o intuito de investigar a temática do currículo na especificidade da área do Ensino de Química no Brasil, o presente trabalho buscou observar brevemente como evoluiu o currículo de química considerando-se o contexto social, econômico e político do país, retomando alguns acontecimentos históricos importantes na sociedade brasileira, bem como as influências advindas de alguns acontecimentos mundiais. Isso porque, de acordo com Santos e Schnetzler (1996, p. 28) "a função do ensino de química deve ser a de desenvolver a capacidade de tomada de decisão, o que implica a necessidade de vinculação do conteúdo trabalhado com o contexto social em que o aluno está inserido". A partir deste pressuposto foram utilizados livros didáticos (LDs) de química como registros históricos e pedagógicos da influência destes fatores diversificados no currículo, realizando a apreciação dos mesmos através da análise de conteúdo e com inspiração nos preceitos da teoria crítica do currículo.

O objetivo desta investigação foi, portanto, analisar - por meio de diferentes livros didáticos - como se relacionam os conteúdos curriculares de química com seus possíveis contextos de utilização/aplicação. Pois se entende que a identificação desta relação nos livros didáticos pode ajudar a entender os valores sociais atribuídos à área da Química e o que se espera do ensino de Química na Educação Básica no Brasil.

É importante considerar, entretanto e por presumido, que as funções ou até a importância do livro didático nas salas de aula vêm mudando rapidamente após o advento das novas tecnologias e o acesso à rede mundial de computadores dentro e fora da escola. O "livro didático" tem virado "tela" e a velocidade de acesso, tanto quanto as mudanças e quantidade de informações que os celulares comportam, acabam por interferir não apenas nas relações de ensino, mas nas metodologias e, principalmente, na fonte de informações que sustenta o andamento das aulas. Para além do reconhecimento das mudanças, cabe destacar que este recurso tem sido um importante balizador de conteúdos, valores, recortes de realidade e, como Hermes (o mensageiro na Mitologia Grega) tem guardado preciosas informações - as quais não são apenas de conteúdo curricular, mas também de valores sociais, de ditames culturais, econômicos e políticos e, certamente, representa um significativo documento histórico. 


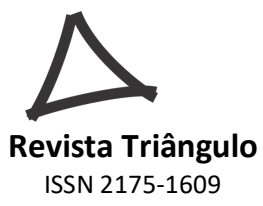

1.1 Breve histórico do currículo de química e as reformas educacionais do Brasil

A busca de uma justificativa para o currículo de química da educação básica brasileira se confunde com a história da própria Educação em nosso país. A perspectiva histórica da Educação está acompanhada das transformações políticas, econômicas, sociais e ideológicas. E, quando se lança o olhar para a retrospectiva da história do país, percebe-se a constante dificuldade de organização (controle, avaliação, atendimento etc.) para um país com dimensões continentais (RIBEIRO, 2003). A primeira ideia de organização escolar no Brasil é da época das capitanias hereditárias no século XVI, da qual se tem registros das primeiras referências escritas sobre a instrução de indígenas que deveriam ser convertidos à fé católica pela catequese (SAVIANI, 2007). Assim, a educação brasileira está vinculada aos acontecimentos do Brasil-colônia e à política colonizadora portuguesa. O processo educacional no Brasil, no final do século XVI e durante o século XVII, estava incorporado a uma política colonial que “[...] objetivava a conquista de um capital necessário à passagem da etapa mercantil para a industrial, do regime capitalista” (RIBEIRO, 2003, p. 29). Portugal não chegou à segunda etapa e, por isso, fez-se necessário tirar o maior proveito da colônia nos séculos XVII e XVIII. Neste período o Brasil experimentou crescimento econômico praticamente nulo em termos de crescimento científico, dada sua dependência de Portugal e a não integração deste ao crescente desenvolvimento econômico europeu (LOPES, 2007).

Em 1759 a Companhia de Jesus ${ }^{1}$ foi expulsa do Brasil, na chamada era pombalina (período em que o Marquês de Pombal foi ministro de Portugal). Sobre a situação da Educação neste período, Marcílio (2005, p. 03) descreve:

No ano da expulsão dos jesuítas do Brasil (1759), os alunos dos colégios, seminários e missões da Companhia de Jesus estavam muito longe de atingir $0,1 \%$ da população brasileira. O único ensino formal existente no Brasil até meados do século XVIII era o oferecido pelos padres da Companhia de Jesus, e ele foi altamente elitista, só atendendo a uma ínfima camada de jovens brancos, proprietários, de famílias de elite colonial. (MARCÍLIO, 2005, p.03).

\footnotetext{
${ }^{1}$ De acordo com Calegari (2014, p. 02) "Em 1534 uma ordem religiosa foi formada por seis estudantes de teologia da Universidade de Paris, com o intuito de contribuir com as necessidades sociais da época, sob a regência da igreja católica romana. Fundamentalmente, o grupo de estudantes pretendia desenvolver trabalho de acompanhamento hospitalar e missionário em Jerusalém ou qualquer outra parte do mundo, onde a igreja católica os enviasse. A ordem religiosa fundada foi denominada Companhia de Jesus".
} 


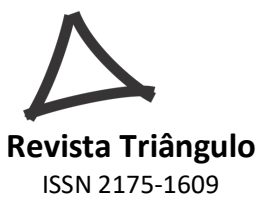

É neste período que surgem as primeiras orientações de um ensino com conteúdo de natureza científica, embora a configuração colonial tenha suprimido os esforços na elaboração de novas linhas educacionais (CARVALHO, 2001). No início do século XIX, mesmo com a instalação da corte portuguesa e a independência do Brasil, a sociedade ainda consistia, em sua maioria, de uma base escravocrata, exigindo apenas uma Educação em base elementar, como as "primeiras letras"2. Em 1835 foram criadas as primeiras escolas normais de formação de professores secundários, mas, ao mesmo tempo e por uma demanda maior da sociedade, se assistia uma proliferação de aulas avulsas e particulares, sem um currículo definido e uma ordem comum a todos para ser seguida (RIBEIRO, 2003). Na busca da organicidade, foram criados dentre algumas instituições o Colégio Pedro II, então idealizado para servir de modelo estrutural às outras unidades e à Educação formal do país, mas não cumpria tais objetivos, em particular no ensino de ciências como descreve Lopes (2007, p. 80),

Articulados a esse contexto cultural mais amplo, havia questões pedagógicas mais específicas que influenciaram o não-desenvolvimento do ensino de ciências, mesmo após a criação do colégio Pedro II, em 1837, com um currículo no qual constavam disciplinas científicas. (...) Havia, na época, o sistema de exames paralelos para os cursos superiores, com a possibilidade de matrículas com aulas avulsas preparatórias. Consequentemente os alunos tendiam a não estudar ciências porque, mesmo os cursos superiores de caráter não-literário, como medicina e cursos das escolas militares e academia da marinha, não exigiam a disciplina em seus exames. (...) Apenas em 1887 noções de ciências físicas e naturais passaram a ser exigidas nos exames de medicina (LOPES, 2007, p.80).

Em 1870 ocorreram reformas que deram importância aos conhecimentos científicos, repetindo-se em 1878, 1881 e no decreto de 1888, no qual se buscava uma formação humana com base na ciência. Em 1879, por exemplo, a Reforma Leôncio de Carvalho trouxe poucas consequências práticas, embora pregasse a liberdade de ensino em cujo âmbito se creditava à prosperidade dos Estados Unidos da América e da Europa. A característica de "transplantação cultural" no campo educacional é destacada por Zotti (2005, p. 35), quando esta afirma que "[...] tradicionalmente, o ensino secundário brasileiro carrega as características das formas culturais europeias [...]".

\footnotetext{
${ }^{2}$ A Lei de 15 de outubro de 1827 determinava que fossem "[...] criadas escolas de primeiras letras em todas as cidades, vilas e lugares mais populosos do Império" (Lei n. 15, 1827).
} 


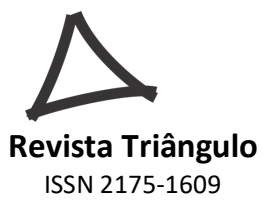

A Reforma Benjamin Constant (1890) foi a primeira reforma educacional após a Proclamação da República e novamente se colocava a formação de ciências na tentativa de minimizar a Educação com base no humanismo clássico (RIBEIRO, 2003). A educação literária deveria ser substituída pela educação científica colocada em razão das influências positivistas. O currículo deveria constar de matemática, astronomia, química, física e biologia. O significado destas mudanças, para Ribeiro (2003, p. 73-74) “[...] foi o acréscimo de matérias científicas às tradicionais, tornando o ensino enciclopédico". Neste período, o currículo de química estava voltado em suas instruções a um ensino de memorização e acúmulo de descrições e informações de caráter utilitarista (LOPES, 2007).

No início do século XX, o Brasil vivia importantes mudanças sociais devido ao aumento das populações urbanas e o início do processo industrial, o qual pressionava o Estado pela escolarização desta população. Foram criadas, então, reformas educacionais, na busca da regulamentação da Educação e, nestas, a presença do ensino de ciências e de química sempre estiveram em desvantagem relativamente ao ensino de humanidades. Essa era a tendência da visão letrada da realidade cultural de países de origem ibérica (LOPES, 2007).

O elevado número de reformas deste período - o Código Epitácio Pessoa (1901), a Reforma Rivadávia (1911), a Reforma Carlos Maximiliano (1915) e a Reforma Luis Alves / Rocha Vaz (1925), esta última incluía a separação das disciplinas de química e física após 63 anos do início do ensino de ciências no Brasil - de certa forma, denota a necessidade da reforma subsequente suprir as incompletudes da reforma anterior. Além disso, evidencia o surgimento de nova conotação para a Educação e o olhar aos modelos internacionais, considerando o alto índice de analfabetismo da população brasileira, que chegava a $85 \%$ em 1890 e foi reduzido em apenas 10\% em 1920 (RIBEIRO, 2003; SCHNETZLER, 2010).

A Reforma Francisco Campos trouxe um aumento da carga horária de ciências ao currículo - notam-se, nesta época, as influências da Escola Nova e dos novos rumos da Ciência associada ao surgimento da indústria, na transição do modelo econômico. Sobre o currículo de química expresso para a última Reforma, Lopes (2007, p. 95) descreve que

O curso secundário passou a ser estruturado em cinco séries, com a química sendo ensinada nas três últimas. Na terceira série (atual primeira série do ensino médio) fazia-se a iniciação ao estudo dos fenômenos químicos e nas demais a abordagem era essencialmente descritiva, englobando metais, ametais e funções orgânicas. Havia também a reordenação do programa de forma coerente, agrupando assuntos correlacionados antes tratados 
desconexamente, tais como catálise, cinética química, termoquímica e equilíbrio químico (LOPES, 2007, p. 95).

As metodologias do ensino de química colocavam tal disciplina como aquela que demonstrava o conhecimento da composição e estrutura íntima dos corpos, suas propriedades e transformações regidas pelas leis, bem como uma orientação voltada ao raciocínio lógico. $\mathrm{O}$ uso de descrições em demasia era predominante e as aulas versavam sobre as características e propriedades das substâncias mais utilizadas (LOPES, 2007).

De 1942 a 1946 foram decretadas as leis orgânicas conhecidas como a Reforma Capanema cujo programa de química vigente nesta Reforma é descrito por Lopes (2007, p. 96):

No programa de química, as então chamadas grandes teorias - estrutura atômica, tabela periódica, radioatividade e temas de físico-química compunham o último tópico do curso e a parte descritiva das substâncias inorgânicas se viu diminuída, abrangendo temas mais gerais, com enfoque mais voltado para aplicações industriais. Foi suprimido o estudo dos ametais $\mathrm{e}$ as funções inorgânicas passaram a ser mais detalhadas. A química orgânica, minuciosamente exposta, ocupava completamente a carga horária da segunda série. No curso clássico, reduziu-se drasticamente a parte descritiva e técnica e tornaram-se predominantes as leis e teorias (LOPES, 2007, p.96).

Sobre a educação na década de 1950, Fracalanza (2006, p. 128) escreve que neste período “[...] foram desenvolvidos diversos e variados movimentos de inovação educacional. Dentre eles, certamente merece destaque o esforço concentrado nas mudanças pretendidas no ensino de ciências em todos os níveis de escolaridade, em especial na educação básica". As influências do período da II Guerra Mundial e Guerra Fria trouxeram fortes mudanças para o ensino de ciências nos Estados Unidos e, consequentemente, para o ocidente, desta vez objetivando a formação de cientistas, engenheiros e técnicos, e isso refletiu fortemente no ensino de ciências no Brasil, particularmente na década de 1960, pela disseminação dos projetos educacionais daquele país (FRACALANZA, 2006; LOPES, 2007).

Em 1961 foi promulgada a nova LDB, responsável pela flexibilização do ensino, com maior tempo destinado ao ensino de ciências, bem como pelo aumento do número de faculdades de filosofia, para a formação de professores habilitados ao desenvolvimento e à expansão do ensino de ciências. Na década de 1960 o Brasil passou por fortes mudanças políticas e sociais, com o contínuo aumento do processo industrial, a concentração 
populacional nas cidades com consequente aumento da demanda de vagas nas escolas, passando particularmente pelo golpe militar de 1964. A ditadura se estendeu até 1985 e, neste período, surgiu a LDB de 1971 (FRACALANZA, 2006). As disciplinas de ciências sofreram mudanças, na busca do caráter profissionalizante, que denotavam as tentativas de modificações educacionais do período, com o objetivo de formação do trabalhador, em detrimento de outras perspectivas (KRASILCHIK, 2000). A partir da década de 80 passou-se por um novo período de reformulações descrito no próximo tópico.

\subsection{As novas reformas educacionais e o livro didático}

Para análise dos livros didáticos neste texto é importante ressaltar as reformulações na educação brasileira nas últimas décadas. A Constituição de 1988 estabeleceu a Educação como garantia que vise à conscientização necessária ao exercício da cidadania como descrito em seu Art. 205: "A educação, direito de todos e dever do Estado e da família, será promovida e incentivada com a colaboração da sociedade, visando ao pleno desenvolvimento da pessoa, seu preparo para o exercício da cidadania e sua qualificação para o trabalho" (BRASIL, 1988). Anos depois, em 1996, a Lei 9.394 estabeleceu as Diretrizes e Bases da Educação Nacional (LDB) e tornou o ensino médio parte da educação básica e com “características finalistas" (Lei n. 9394, 1996). Os Parâmetros Curriculares Nacionais do Ensino Médio (PCNEM), em 1997 e 2000, e PCN+ em 2002, propuseram mudanças fundamentadas em três grandes áreas de conhecimento: "Linguagens, Códigos e suas Tecnologias"; "Ciências da Natureza, Matemática e suas Tecnologias" e "Ciências Humanas e suas Tecnologias", visando desde logo a interdisciplinaridade e a contextualização dos conteúdos, trazendo propostas abrangentes como os temas estruturadores. Neste sentido, em artigo sobre o tema, Alves et al. (2016, p. 6) afirmam que:

Os PCNEM têm sido interpretados como um eixo de proposições. Preocupou-se em promover a ideia de um Ensino Médio no qual o aluno não saísse especialista em área alguma, mas que saísse possuidor de um conhecimento que lhe desse condições de entender a tecnologia que o cerca e de exercer seu papel de cidadão na sociedade atual. (...) almeja-se um Ensino Médio capaz de atender tanto aos alunos que queiram prosseguir os estudos, quanto àqueles que irão rumo ao mercado de trabalho e à vida profissional. (...) o ensino de ciências deve ser realizado de modo a refletir aspectos importantes no cotidiano do aluno, de modo a torná-lo capaz de tomar decisões (ALVES, SILVA \& ANDRADE, 2016, p. 6). 


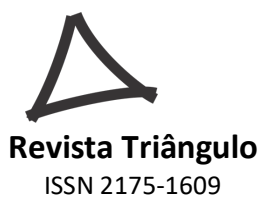

Desde então, não foram observadas mais alterações significativas nos documentos que orientam o ensino no país, exceto pela atual modificação proposta para o Ensino Médio com a entrada em vigor da Medida Provisória $n^{\circ}$ 746, de 2016, oriunda do anterior Chefe do Poder Executivo Federal e convertida na Lei 13.415/2017. Esta, porém, não especifica os conteúdos a serem abordados, mas tão somente regulamenta alguns aspectos estruturais do Ensino Médio, ficando tal especificação sob a responsabilidade de documento unificador do ensino no país, o qual cumpre o previsto no Plano Nacional de Educação (PNE), instituído em 2014, pela Lei $n^{\circ} 13.005 / 2014$ (Lei n. 13005, 2014). O novo documento com ênfase na unificação do ensino no Brasil - Base Nacional Curricular Comum (BNCC) - enfatiza que comuns são as aprendizagens essenciais, mas não os currículos, sendo resguardadas as autonomias para a construção destes, pelos entes federais e respectivas instituições de ensino.

É neste período, a partir da década de 1980, que o livro didático (LD) ganhou notoriedade na educação básica. Embora a relação entre LD e o Estado tivesse início em 1938, com as primeiras regulamentações da sua produção, o cenário mais próximo do atual aconteceu em 1984, com o MEC atuando como comprador de livros das editoras participantes do Programa do Livro Didático. Em 1985, o Programa passou a ser denominado Programa Nacional do Livro Didático (PNLD) e em 2004, foi criado o PNLEM, Programa Nacional do Livro Didático para o Ensino Médio (HOFLING, 2000). O PNLD foi unificado em 2010 quando a avaliação, escolha e aquisição se tornaram vinculadas em um só Programa para todas as séries do Ensino Básico (ECHEVERRIA, MELLO \& GAUCHE, 2010) (LEÃO \& MEGID NETO, 2006).

Os estudos voltados ao tema do LD se intensificaram em décadas anteriores tomando como referência o trabalho de Francisco Albuquerque (1976), no qual busca despertar nos estudantes acadêmicos a relevância e importância do livro como objeto de estudo e pesquisa (ALBUQUERQUE, 1976; FRACALANZA, 2006), seguido de vários artigos e revisões bibliográficas (MEGID NETO \& FRACALANZA, 2003; HOFLING, 2000; RODRIGUES, 2014; SCHNETZLER, 1981).

Como recurso expresso do currículo aqui discutido, Lopes (2007, p. 212) postula que a atual atenção dada ao LD demonstra

Uma concepção de currículo na qual o livro didático é visto como o orientador pedagógico do trabalho do professor. Tal perspectiva se associa a valorização de uma matriz curricular a ser apresentada a todas as escolas,

v.12

n.1

p. 43-67

Jan./Abr. 
articulada à compreensão do valor de uma cultura comum. O livro didático é tido como um padrão curricular desejável, mesmo quando se considera a possibilidade de que ele seja modificado de alguma forma. (...) Assim, existe a tendência de buscar a leitura unívoca do livro didático e a elaboração do livro didático ideal, algo que, por exemplo, não é esperado nem desejado dos livros não didáticos (LOPES, 2007, p. 212).

Nas discussões sobre o papel do LD na aprendizagem sempre se depara com situações nas quais o livro, além de ser praticamente o único recurso usado, ainda é, predominantemente, o mais importante para os professores da rede pública de ensino, muitas vezes ainda se tornando um recurso completo para textos, ilustrações e atividades gerais (AMARAL, 2006).

Sobre os LDs de química, a pesquisadora Schnetzler (1981), em seu trabalho sobre os livros secundários de química, do período de 1875 (ano da publicação do primeiro livro didático de química no Brasil) a 1978, constatou forte defasagem entre as propostas dos LDs e as proposições legais definidas nas cinco reformas educacionais deste período, apresentadas no tópico anterior, sendo menor essa defasagem no período referente à Reforma Francisco Campos. Outra constatação da autora é que, de forma geral, os LDs necessitavam de uma interferência transformadora do professor para não refletirem as características do ensino tradicional, em muitos casos negligenciando o aspecto investigativo, sua aplicação social e o desenvolvimento da criticidade nos alunos.

A partir deste cenário de importância atribuída ao LD destaca-se a relevância de estudos voltados ao tema, à luz dos mais variados elementos que auxiliem na discussão e conhecimento acerca do currículo de química e ciências presente nos mesmos. Buscou-se, até este ponto, mesmo que de forma tangencial, relacionar o ensino, particularmente de ciências e química, com a dinamicidade das mudanças sociais, econômicas e políticas, ao longo da história do Brasil. Estas relações podem ser observadas e analisadas nos escritos dos documentos oficiais que regulamentam a Educação e nos currículos prescritos nos documentos escolares, dos quais o LD tem se consolidado como um dos mais importantes.

Desta forma, com fundamento nos aspectos apresentados até o momento, foi analisado um conjunto de seis LDs, buscando-se identificar aspectos sociais, políticos e econômicos por meio da identificação de conteúdos curriculares e de temas de estudo presentes nesses materiais. 


\section{MATERIAIS E MÉTODOS}

Com base nos preceitos da análise de conteúdo foram analisados 6 livros didáticos: 2 livros (LD1 e LD2) do $9^{\circ}$ ano do Ensino Fundamental, de autores/editoras distintos, com anos de edição 2010 e 2015, participantes da escolha das duas últimas edições do PNLD; e 4 livros do Ensino Médio (LD3, LD4, LD5 e LD6) correspondentes ao $1^{\circ}$ volume de coleções e/ou autores/editoras distintos, utilizados no $1^{\circ}$ ano do Ensino Médio, dentre os quais 3 deles participaram do PNLD do triênio 2015-2017, com anos de edição entre 2013 e 2014, e 1 deles com ano de edição em 1979 (LD6). Segundo Caregnato e Mutti (2006, p. 682),

A maioria dos autores refere-se à $\mathrm{AC}$ como sendo uma técnica de pesquisa que trabalha com a palavra, permitindo de forma prática e objetiva produzir inferências do conteúdo da comunicação de um texto replicáveis ao seu contexto social. $\mathrm{Na} \mathrm{AC}$ o texto é um meio de expressão do sujeito, onde o analista busca categorizar as unidades de texto (palavras ou frases) que se repetem, inferindo uma expressão que as representem (CAREGNATO \& MUTTI, 2006, p. 682).

A partir do estudo da palavra e de seu significado e, considerando a possibilidade de identificação de recorrências e ênfases de certos termos, os livros didáticos foram analisados buscando-se recorrências, divergências e os possíveis motivos (políticos, econômicos e sociais) que justifiquem a presença desses termos no material. Assim, foram estabelecidas duas categorias de análise: conteúdos curriculares semelhantes e temas contextuais.

Os conteúdos foram organizados, primeiramente, em listas gerais representando o currículo formal com o intuito de comparar os LDs entre si. Destes conteúdos foram expostos os temas contextuais em diferentes níveis - da simples citação até uma perspectiva mais crítica - a partir dos quais se analisou as influências e/ou justificativas destes temas estudados em uma perspectiva de relacioná-los aos preceitos da teoria crítica do currículo.

\section{ANÁLISE DOS DADOS E RESULTADOS}

Os principais conteúdos curriculares dos seis LDs foram transpostos para um quadro (quadro 1) no qual é possível comparar de forma mais eficiente a estrutura básica da organização destes, bem como as principais semelhanças e/ou diferenças entre eles. 


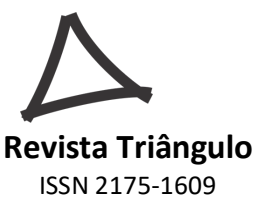

$(\Theta \Theta \Theta$

Quadro 1: Lista de conteúdos curriculares dos LDs.

\begin{tabular}{|l|l|l|l|l|l|l|}
\hline Conteúdos (Ordenados na mesma sequência dos LDs) & LD1 & LD2 & LD3 & LD4 & LD5 & LD6 \\
\hline Ano de Edição & $\mathbf{2 0 1 0}$ & $\mathbf{2 0 1 5}$ & $\mathbf{2 0 1 3}$ & $\mathbf{2 0 1 4}$ & $\mathbf{2 0 1 4}$ & $\mathbf{1 9 7 9}$ \\
\hline & \multicolumn{2}{|c|}{ E. F. } & \multicolumn{5}{|c|}{ E. M. } \\
\hline Grandezas físicas e unidades de medida & $\mathrm{x}$ & $\mathrm{x}$ & $\mathrm{x}$ & $\mathrm{x}$ & $\mathrm{x}$ & \\
\hline Transformações físicas e químicas & $\mathrm{x}$ & $\mathrm{x}$ & $\mathrm{x}$ & $\mathrm{x}$ & $\mathrm{x}$ & $\mathrm{x}$ \\
\hline Estados de agregação da matéria & $\mathrm{x}$ & $\mathrm{x}$ & $\mathrm{x}$ & $\mathrm{x}$ & $\mathrm{x}$ & $\mathrm{x}$ \\
\hline Propriedades da matéria/substâncias & $\mathrm{x}$ & $\mathrm{x}$ & $\mathrm{x}$ & $\mathrm{x}$ & $\mathrm{x}$ & $\mathrm{x}$ \\
\hline Substâncias e misturas / separação de misturas & $\mathrm{x}$ & $\mathrm{x}$ & $\mathrm{x}$ & $\mathrm{x}$ & $\mathrm{x}$ & $\mathrm{x}$ \\
\hline Abordagem histórica: alquímica e método científico & & $\mathrm{x}$ & & $\mathrm{x}$ & $\mathrm{x}$ & \\
\hline Gases & & & & $\mathrm{x}$ & $\mathrm{x}$ & \\
\hline Teoria atômica & $\mathrm{x}$ & $\mathrm{x}$ & $\mathrm{x}$ & $\mathrm{x}$ & $\mathrm{x}$ & $\mathrm{x}$ \\
\hline Radioatividade & $\mathrm{x}$ & & $\mathrm{x}$ & $\mathrm{x}$ & $\mathrm{x}$ & \\
\hline Linguagem química: fórmulas e equações químicas; & $\mathrm{x}$ & $\mathrm{x}$ & $\mathrm{x}$ & $\mathrm{x}$ & $\mathrm{x}$ & $\mathrm{x}$ \\
\hline Leis ponderais e/ou reações químicas & $\mathrm{x}$ & $\mathrm{x}$ & $\mathrm{x}$ & $\mathrm{x}$ & $\mathrm{x}$ & $\mathrm{x}$ \\
\hline Mol e/ou estequiometria & $\mathrm{x}$ & $\mathrm{x}$ & $\mathrm{x}$ & $\mathrm{x}$ & & \\
\hline Tabela Periódica & $\mathrm{x}$ & $\mathrm{x}$ & $\mathrm{x}$ & $\mathrm{x}$ & $\mathrm{x}$ & $\mathrm{x}$ \\
\hline Ligações químicas & $\mathrm{x}$ & $\mathrm{x}$ & $\mathrm{x}$ & $\mathrm{x}$ & $\mathrm{x}$ & $\mathrm{x}$ \\
\hline Polaridade e geometria das moléculas & & & $\mathrm{x}$ & $\mathrm{x}$ & $\mathrm{x}$ & \\
\hline Forças intermoleculares & & & $\mathrm{x}$ & $\mathrm{x}$ & $\mathrm{x}$ & \\
\hline Funções inorgânicas & $\mathrm{x}$ & $\mathrm{x}$ & $\mathrm{x}$ & & $\mathrm{x}$ & $\mathrm{x}$ \\
\hline Reações de oxirredução & & & $\mathrm{x}$ & & & $\mathrm{x}$ \\
\hline
\end{tabular}

Fonte: os autores.

\subsection{Conteúdos curriculares semelhantes}

Quando se observa os LDs em conjunto, quer sejam os do $9^{\circ}$ ano do Ensino Fundamental ou os do $1^{\mathrm{o}}$ ano do Ensino Médio, percebe-se a repetição de temas centrais do currículo de química: estados físicos e propriedades da matéria, misturas e métodos de separação, atomística, tabela periódica, ligações químicas, os primeiros conceitos sobre reações químicas e funções inorgânicas. Dentre os LDs do Ensino Médio evidenciou-se pouca variação de conteúdo, por exemplo, o LD3 não aborda o tema gases e o LD5 não aborda noções de reações químicas, como estequiometria. O LD 6, da década de 1970, também apresenta similaridade na lista de conteúdos dos LDs editados depois de quase quatro décadas. Os LDs 1 e 2 (do Ensino Fundamental) apresentam praticamente o mesmo conteúdo curricular, variando apenas no tema radioatividade.

Em artigo de 1995, portanto antes da LDB de 1996, Zanon e Palharini denunciam os paradoxos do ensino de química no Ensino Fundamental. Segundo as autoras os livros traziam a química por apenas um semestre na antiga $8 .^{\text {a }}$ série (hoje 9. ${ }^{\circ}$ ano), mas que, em contrapartida

\begin{tabular}{l|l|l|l|l|l|l} 
(C) Revista Triângulo & Uberaba, MG & v.12 & n.1 & p. 43-67 & Jan./Abr. & 2019
\end{tabular}


“[...] os temas estudados em ciências nas séries anteriores são o ar, a água, o solo, alimentos e alimentação, saúde, meio ambiente, higiene, seres vivos, transformações, fenômenos, energia, ciclos de vida, corpo humano. Vale perguntar: esses temas não são assuntos de química?’. Foram estudos e questionamentos como estes que sustentaram mudanças importantes na matriz curricular do ensino de ciências no Brasil. E, atualmente, as editoras preocupam-se em trazer os conteúdos de modo mais interdisciplinar, contextualizado e, mesmo que discretamente, distribuído ao longo do segundo ciclo do ensino Fundamental.

De todo modo, conforme verificado no quadro acima, permanece ainda o fato de que o Ensino Médio e o Ensino Fundamental apresentam listas de conteúdo similares, o que conduz à indagação dos objetivos curriculares destas duas etapas. As diferenças ocorrem no aprofundamento dos conteúdos, embora, muitas vezes, apresentem as mesmas abordagens descritivas. Tal repetição de conteúdos pode atender a um dos objetivos propostos pela LDB de 1996 para o Ensino Médio - objetivos estes de consolidação e aprofundamento dos conhecimentos adquiridos no Ensino Fundamental, a fim de que o aluno possa prosseguir os estudos (Lei n. 9394, 1996). Por sua vez, os PCN para as ciências naturais descrevem uma função para o Ensino Fundamental que privilegia uma formação não tão arraigada ao saber futuro do aluno no ensino de ciências:

Ao se considerar ser o ensino fundamental o nível de escolarização obrigatório no Brasil, não se pode pensar no ensino de ciências como um ensino propedêutico, voltado para uma aprendizagem efetiva em momento futuro. A criança não é cidadã do futuro, mas já é cidadã hoje, e nesse sentido, conhecer ciência é ampliar a sua possibilidade presente de participação social e viabilizar a sua capacidade plena de participação social no futuro (BRASIL, 1997).

O documento acima citado é datado de 1997 e, importante ressaltar que, em 11 de novembro de 2009 foi promulgada a Emenda Constitucional $n^{\circ} 59$ que estabeleceu o prazo até 2016 para a ampliação da obrigatoriedade da educação básica, passando esta a ser dos 4 aos 17 anos, portanto, o ensino Médio passou a ser também obrigatório.

$\mathrm{Na}$ citação são observados dois posicionamentos relevantes, um descrevendo a importância do retorno, enquanto metodologia de ensino, e o outro descrevendo a formação por etapas acabadas. Considerado historicamente, o Ensino Fundamental já foi a etapa final da Educação Básica no Brasil e, atualmente, é apenas mais uma etapa até o Ensino Médio, então, é provável que os conteúdos definidos permaneçam até por um habitus ainda não alterado, por 
exemplo, pela tradição educacional. Atualmente, sob a ótica da BNCC, pretende-se que no Ensino Médio haja um aprofundamento das temáticas já abordadas no Ensino Fundamental: matéria e energia, vida e evolução, Terra e Universo (BRASIL, 2017), fazendo jus à manutenção da "repetição" dos conteúdos do $9^{\circ}$ ano, no $1^{\circ}$ ano do Ensino Médio. Ainda em relação à $\mathrm{BNCC}$, é imprescindível destacar que a mudança na previsão de conteúdos é nítida principalmente quando se considera que o conteúdo de Ciências, tanto do Ensino Fundamental quanto do Médio, encontra-se unido em única área denominada "Ciências da Natureza", a qual compreende Física, Química e Biologia (BRASIL, 2017).

É válido ressaltar que determinados LDs, como os neste trabalho avaliados, trazem um programa extenso de conteúdos exigidos nos vestibulares para o ingresso nas instituições de ensino superior. Sobre este aspecto dos conteúdos dos LDs, Echeverria et al. (2010, p. 227) descrevem que,

$\mathrm{Na}$ década de 60 , com o surgimento da chamada indústria dos cursinhos preparatórios, observa-se a produção de apostilas utilizadas com o fim especifico de adestramento para os diversos vestibulares, muitas das quais foram transformadas em livros didáticos (...). Este adestramento inclui a imprescindível abrangência quantitativa de todo o conteúdo previsto para as provas dos vestibulares almejados, não se permitindo maiores preocupações com o processo ensino-aprendizagem (ECHEVERRIA, 2010, p. 227).

É possível observar que em determinadas propostas em que se busca discutir certa temática de forma mais abrangente através de aspectos importantes como economia e sociedade, estas propostas sempre trazem inúmeros exercícios de vestibular ao final dos tópicos ou capítulos e alguns deles não possuem qualquer relação direta com a abordagem do conteúdo, denotando que tais atividades são mantidas na tentativa de adequação às diferentes demandas atuais dos LDs. Tal formato de exposição de conteúdos remete aos antigos ideais propostos desde a Reforma Benjamin Constant (LOPES, 2007), na qual o currículo de química tinha forte apelo à memorização e acúmulo de informações, dando sustentação, como consequência, às características dos vestibulares desde a década de 1960.

A questão, entretanto, não se refere à simples identificação de repetição de conteúdos, pois o modelo do currículo em espiral, com origem nos trabalhos de Jean Piaget e Jerome Bruner foram fortemente difundidos e forneceram as bases para um modelo educacional que repercute nos livros didáticos. Isso porque este modelo segue as premissas de que o aprofundamento crescente é uma forma de permitir que todos os alunos possam ter acesso ao 
conteúdo em diferentes momentos de sua carreira acadêmica, visando o aprofundamento crescente de seu conhecimento (SILVA \& GOMES, 2017). Os livros didáticos ao serem propostos dessa forma, convergem para uma concepção de aprendizagem que considera o desenvolvimento cognitivo do aluno como um processo.

A questão mais ampla pauta-se, entretanto, nos fatos de que, primeiro, tem-se um histórico de traduções de livros estrangeiros (MORI \& CURVELO, 2014), os quais são compilados de informações com grande quantidade de conteúdos - e a supressão de conteúdo nos dias atuais acaba sendo sempre um assunto controverso, o qual contrapõe a possibilidade de aceso à pertinência de certos conteúdos em diferentes níveis de ensino. Em segundo lugar há que se considerar a anterior obrigatoriedade do ensino até 14 anos, fazendo com que esse conteúdo (muitas vezes presente também em livros do ensino superior) fosse condensado no último ano do ensino Fundamental. A mudança dessa obrigatoriedade para os 17 anos talvez possa vir a interferir nos conteúdos dos livros didáticos nas próximas décadas fazendo com que a repetição seja trazida de outras formas e/ou que o ensino fundamental acabe tendo menos conteúdos específicos da química, ficando estes alocados apenas no ensino Médio.

Em extensa e profunda revisão sobre a história dos livros didáticos de química no Brasil do início do século XIX até 1930, Mori e Curvelo (2014, p. 924) afirmam que estes

[...] constituem uma fonte de interesse para a historiografia das ideias químicas no Brasil, da educação e mesmo da filosofia brasileira (vide, por exemplo, o aspecto positivista do livro Apontamentos de Chimica). Estas obras apresentam elementos nem sempre encontrados nos livros atuais, embora almejados pelos especialistas do campo da Educação em Ciências, como o tratamento dos conteúdos que enfatize sua compreensão, a organização lógica, fundamentada e coerente, e a abordagem crítica de questões da história e da filosofia da ciência (MORI \& CURVELO, 2014, p. 924).

Além disso, os autores citam o trabalho de Mortimer e Santos, e afirmam que de 1930 até 1960 houve uma progressiva homogeneização em forma e conteúdos dos livros didáticos e, pela investigação apresentada neste artigo, percebe-se que a homogeneização permanece em termos de conteúdos, mas varia grandemente na quantidade de imagens, na diversidade de fontes de informação compiladas nos textos e nas tentativas de contextualização dos temas abordados. 
Por fim, nota-se que o conteúdo presente nos LDs de química apreciados, em muito se assemelham aos conteúdos trazidos nas leis (de 1942 a 1946) que constituíram a denominada Reforma Capanema, enfatizando as "grandes" teorias (atômica, radioatividade, tabela periódica, etc.), as funções inorgânicas, e com pouco (ou nenhum) conteúdo da parte da química descritiva (LOPES, 2007, p.96). Percebe-se, portanto, que as mudanças efetivas são lentas, conduzindo à conclusão que o currículo em sentido lato demora anos para se adequar e mantém, não raramente, traços intensos de sua configuração anterior.

\subsection{Temas contextuais}

Foram investigadas nos LDs as associações dos conteúdos curriculares com o cotidiano, observando a presença de determinados temas que apresentem relações com aspectos de conotação política, social, econômica ou cultural em diferentes níveis. Os temas encontrados seguem descritos no quadro 2.

Quadro 2: Temas mais abordados nos LDs analisados.

\begin{tabular}{|c|c|c|c|c|c|c|}
\hline Tema & LD 1 & LD 2 & LD 3 & LD 4 & LD 5 & LD 6 \\
\hline Ano de Edição & 2010 & 2015 & 2013 & 2014 & 2014 & 1979 \\
\hline & \multicolumn{2}{|c|}{ E. F. } & \multicolumn{4}{|c|}{ E. M. } \\
\hline Consumismo & & & & $\mathrm{x}$ & $\mathrm{x}$ & \\
\hline Reciclagem & $\mathrm{x}$ & & $\mathrm{x}$ & $\mathrm{X}$ & $\mathrm{X}$ & \\
\hline Clima e correntes marítimas & & & $\mathrm{x}$ & & $\mathrm{x}$ & \\
\hline Alimentos & & $\mathrm{x}$ & & $\mathrm{x}$ & $\mathrm{x}$ & \\
\hline Controle de qualidade & & & & $\mathrm{x}$ & & \\
\hline Aquecimento global / efeito estufa & & $\mathrm{x}$ & $\mathrm{x}$ & & $\mathrm{x}$ & \\
\hline Petróleo e combustíveis & $\mathrm{x}$ & $\mathrm{x}$ & $\mathrm{x}$ & $\mathrm{x}$ & $\mathrm{x}$ & \\
\hline Água & & & $\mathrm{X}$ & $\mathrm{X}$ & $\mathrm{X}$ & \\
\hline Tratamento de água & & & $\mathrm{x}$ & $\mathrm{x}$ & $\mathrm{x}$ & \\
\hline Tratamento de esgoto & & & $\mathrm{X}$ & $\mathrm{x}$ & & \\
\hline Lixo & & $\mathrm{x}$ & $\mathrm{x}$ & $\mathrm{x}$ & $\mathrm{x}$ & \\
\hline Aparelhos eletrônicos & & & $\mathrm{x}$ & $\mathrm{x}$ & & \\
\hline Radiação eletromagnética & & & $\mathrm{X}$ & $\mathrm{x}$ & & \\
\hline Metais & $\mathrm{x}$ & $\mathrm{x}$ & $\mathrm{x}$ & $\mathrm{x}$ & & \\
\hline Sabões e detergentes & & & & & $\mathrm{x}$ & \\
\hline Poluição atmosférica & & & $\mathrm{x}$ & & $\mathrm{x}$ & \\
\hline Plásticos & & & $\mathrm{X}$ & & & \\
\hline Chuva ácida & & $\mathrm{x}$ & $\mathrm{X}$ & & $\mathrm{X}$ & \\
\hline Agrotóxicos & & & & & $\mathrm{X}$ & \\
\hline Agricultura & & & & & $\mathrm{x}$ & \\
\hline Camada de ozônio e radiação UV & $\mathrm{X}$ & $\mathrm{X}$ & $\mathrm{X}$ & & $\mathrm{X}$ & \\
\hline
\end{tabular}

\begin{tabular}{l|l|l|l|l|l} 
(C) Revista Triângulo & Uberaba, MG & v.12 & n.1 & p. 43-67 & Jan./Abr.
\end{tabular}




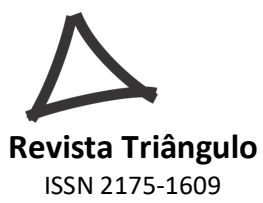

Fonte: os autores.

Os temas apresentados no quadro 2 que aparecem nos LDs 1-5 apresentam exemplos do cotidiano em seus tópicos das mais diversas formas: figuras ilustrativas de exemplos, leituras complementares com temas ambientais, sociais, econômicos, etc., citações ao longo do conteúdo que se associam ao cotidiano de forma geral, bem como atividades norteadoras de discussões envolvendo determinados conteúdos com cenários mais abrangentes. O LD 6 não apresenta contextualização alguma dos conteúdos desenvolvidos em qualquer nível de abordagem que possam ser minimamente comparados aos temas apresentados no quadro 2 (neste LD aparecem pequenas referências de aplicações, por exemplo, a citação ao uso do alambique no preparo de bebidas alcoólicas como uma tentativa de ilustrar aplicações à destilação). Os LDs 3-5, voltados ao Ensino Médio, possuem um volume superior de abordagens relacionadas ao cotidiano. Os LDs 1 e 2, para o Ensino Fundamental, apresentam poucos temas, talvez pela limitação de espaço, haja vista o fato de no $9^{\circ}$ ano os alunos estudarem química apenas em um semestre, sendo o outro destinado à física (abordagem não realizada neste texto).

Pode-se ainda evidenciar, pelas informações do quadro 2, o fato de os LDs, através destes temas, demonstrarem que os conteúdos e os objetos de estudos estão interligados a processos naturais, industriais e de avanços tecnológicos, bem como alguns temas surgem a partir de tendências sociais, econômicas e políticas, como aqueles voltados aos assuntos decorrentes da preservação ambiental, a exemplo do tema lixo, da reciclagem, do tratamento de esgotos, do efeito estufa, etc., temas ausentes no LD 6 de quatro décadas atrás quando, por exemplo, eram mínimas as discussão sobre os temas ambientais da atualidade; ou ainda, como o tema petróleo que está sempre exposto nos conteúdos referentes à separação de misturas, haja vista a conotação adquirida pelo assunto desde a sua descoberta no Brasil, da sua importância em vários setores no cenário mundial, além dos conflitos econômicos e políticos causados pelo mesmo.

Nota-se que em sua maioria os temas são apresentados na forma de leituras complementares comuns a todos os LDs, apenas variando os tamanhos dos textos e a interpretação, mas com abordagem relativamente similar. Em alguns casos, os temas são considerados sobremaneira relevantes ao cotidiano e, por esta razão, são norteadores da organização do LD. Neste sentido, o LD5, por exemplo, divide sua organização em três 
grandes temas: consumo sustentável, poluição atmosférica e agricultura. Entende-se que estas aparições são tentativas dos autores dos LDs em corroborar a importância dos conteúdos a serem estudados na forma de contextos que poderiam ser importantes para a sociedade de forma geral.

Buscou-se nos LDs um pouco das concepções que corroboram a formulação do currículo expresso e descrito nos quadros anteriores. Para tanto, foram escolhidos alguns temas, muitas vezes comuns a todos os livros. Importante destacar que não se tentou justificar, simplesmente, a existência de determinado conteúdo no currículo apenas pela aparição daquele contexto expresso em uma leitura complementar, ou de uma função cotidiana daquele objeto de estudo, mas apenas foram enfatizados alguns indicadores de como o próprio LD justifica aos alunos e professores uma possível forma de facilitar e aprimorar a inserção destes conteúdos no currículo formal, abrindo portas para a abordagem crítica do mesmo. Não se pode perder de vista que a formação ampla do indivíduo não se fará mediante a simples contextualização através de pequenas associações de conteúdos com acontecimentos aleatórios do cotidiano, fato sempre pontuado por Santos (2007, p. 04) ao afirmar que

[...] muitos professores consideram o princípio da contextualização como sinônimo de abordagem de situações do cotidiano, no sentido de descrever, nominalmente, o fenômeno com a linguagem científica. Essa abordagem é desenvolvida, em geral, sem explorar as dimensões sociais nas quais os fenômenos estão inseridos (SANTOS, 2007, p. 04).

A amplitude da relação entre os conteúdos do currículo e seu papel em uma formação libertadora, na perspectiva de Paulo Freire, colocada por Santos (2007, p. 05) como uma visão de "[...] mediatização dos saberes por uma educação problematizadora, de caráter reflexivo, de arguição da realidade, na qual o diálogo começa a partir da reflexão sobre contradições básicas de situações existenciais, consubstanciando-se na educação para a prática da liberdade", vai muito além das fronteiras que encerram os currículos de química nos LDs das últimas décadas.

Neste sentido, no LD 4, o tema lixo é abordado de forma aprofundada associado a tópicos como preservação do meio ambiente, separação seletiva do lixo, reciclagem, consumo ao longo da história, abordagem de materiais através do ciclo de vida de embalagens, coleta do lixo e seu destino final, cidade limpa e até questões econômicas no uso do lixo - como fonte de renda. A abordagem deste tema é recente no currículo e obedece a uma demanda 
oriunda dos altos níveis de consumo atuais, da exploração aumentada dos recursos naturais com o crescimento da população, bem como dos problemas ambientais causados pelo lixo, além dos problemas mais imediatos ocasionados à população, como o entupimento de bueiros nas grandes cidades. O tema e a abordagem neste LD trazem questões que atendem ao currículo crítico, transcendendo o conhecimento sobre os conteúdos químicos para uma discussão política, econômica, social, cultural e ética. Apresentam elementos que se aproximam de um tratamento do currículo relacionado aos diversos contextos de uma perspectiva crítico-emancipatória (MENEZES \& SANTIAGO, 2014).

O LD 5 apresenta ao longo dos seus conteúdos a problemática do consumismo discutindo várias vertentes dos meios de produção relacionados a conteúdos químicos, como propriedades de materiais e separação de misturas, e demonstrando os diversos impactos na sociedade gerados pelo comportamento consumista da sociedade atual, alertando o indivíduo sobre as mudanças que provocamos em nosso meio social e ambiental e como podemos atuar nestas questões.

No entanto, outros temas como os 'metais', por exemplo, cuja importância está conectada à história da humanidade, desde os primórdios e, atualmente, através do seu alto consumo, também necessita de abordagens mais amplas e críticas - como aquela apresentada pelo LD4 com o tema lixo -, embora 4 dos 5 LDs tenham realizado algum tipo de abordagem. Uma formação mais ampla da população sobre temas como "exploração de minérios" pode alertar a população sobre crimes contra a natureza como o desastre ambiental de Mariana/MG, em 2015 e de Brumadinho/MG em 2019, os quais chamaram a atenção do Brasil e do mundo sobre a extração de minérios, cujo setor até então não demonstrava explicitamente as vertentes negativas da exploração de metais comuns ao cotidiano, como o ferro. Acontecimentos como estes trazem a reflexão da necessidade de novas abordagens e discussões críticas sobre o conteúdo no currículo dos cursos de química. Nesse sentido, a simples descrição dos processos de mineração e de separação de misturas, ou a nomeação de sais e das propriedades físico-químicas poderiam ser analisados de modo a provocar posturas outras diante deste tipo de acontecimento, mas que, via de regra, estagnam-se na imobilidade da pouca condição de (ou conhecimento para) tomadas de decisões mais críticas.

Importante destacar que o contato (e o acesso cada vez maior) das pessoas com a Internet tem causado uma série de mudanças no que se refere à função desses livros e, as 

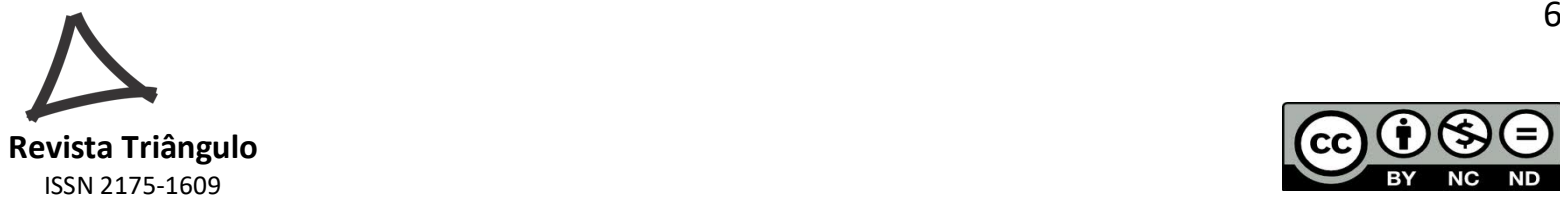

novas formas de organização e estruturação dos LDs consideram que a função de 'levar informação' à sala de aula tem sido cada vez mais deslocada. O caso dos acidentes supracitados mostra isso: o professor, querendo trabalhar estes acontecimentos com seus alunos, não encontrará a informação no livro, mas sim nos jornais e redes online, porém os conteúdos químicos sobre processos de separação de mistura, lixiviação, metais pesados, propriedades físico-químicas, etc. poderão ser encontrados no livro - e isso poderá sustentar uma problematização e contextualização dos conteúdos.

Os LDs do $9^{\circ}$ ano do Ensino Fundamental e $1^{\circ}$ ano do Ensino Médio estão geralmente pautados na construção de modelos que permitam ao aluno entender as ideias de partículas, átomos, moléculas e ligações químicas. Neste sentido, os LDs nem sempre apresentam relações cotidianas, fenômenos naturais ou contextualizações para determinados conteúdos, como a atomística. Para Machado e Mortimer (2007, p. 29) conteúdos como a atomística são importantes pois "[...] o conhecimento das substâncias e dos materiais passa necessariamente pelo conhecimento de suas propriedades, no entanto para explicar o comportamento dos materiais e mesmo essas propriedades, precisamos lançar mão de alguns conhecimentos químicos relacionados à constituição desses materiais e substâncias”.

O esgotamento de determinados conteúdos sem associação à prática e a outros conteúdos que justifiquem o uso destes tornam, entre outras coisas, o ensino de química do $1^{\mathrm{o}}$ ano do Ensino Médio, e também metade do último ano de Ensino do Fundamental (cujo currículo é semelhante), desvinculado da realidade de seus alunos, fora de contextos e objetivos palpáveis, uma vez que esta etapa está pautada em conteúdo de nível microscópico e abstrato em suas compreensões fragmentadas.

Tendo em vista os objetivos inerentes à educação científica e ao ensino de química, regulamentados pelos documentos governamentais abordados na introdução deste trabalho, os quais, portanto, representam os LDs, Lima e Silva (2007, p. 92) observaram, em meados de 2007, que não havia conexão entre os dois,

Nos últimos anos essa tradição vem sendo confrontada pela necessidade de rever e rediscutir os critérios atualmente adotados para a seleção e sequenciação dos conteúdos de ensino, tendo em vista a função social da escola no ensino fundamental. Num contexto de insatisfação, indefinição e debate, muitas têm sido as demandas por reformas curriculares para o ensino de ciências. Não nos escapa, contudo, a avaliação de que há uma enorme defasagem entre aquilo que se propõe nos documentos oficiais de governo ( $\mathrm{PCN}, \mathrm{PCN}+$, propostas curriculares das secretarias de estado, etc.) e os 
SILVA, 2007, p. 92)

Este aspecto se aproxima dos resultados encontrados por Schnetzler (1981) e apresentados na introdução deste texto, em cujas linhas se verificou o fato de os LDs historicamente não demonstrarem afinidades com grande parte das proposições expostas nestes textos governamentais. Atualmente, alguns temas contextuais são discutidos nos LDs, como se pode observar no quadro 2, a exemplo das várias referências ao meio ambiente, através de tópicos como o efeito estufa, a camada de ozônio, o tratamento de água e esgoto, o lixo, etc. Neste último quesito, os LDs atuais se aproximam das proposições dos documentos regulatórios da Educação ao buscarem evidenciar a relevância dos temas estudados e, em alguns casos, a abordagem crítica do mesmo.

Por fim, em relação à BNCC, fica evidente uma nova ênfase no que se refere aos temas contextuais - os quais se demonstram bastante permeados por tecnologia aplicada e novas descobertas científicas, tais como radiação aplicada à medicina diagnóstica, técnicas envolvendo alterações no DNA, mídia digital, etc. Neste sentido, dos temas contextuais contidos nos LDs apresentados, apenas os temas alimentos, controle de qualidade, efeito estufa, água, aparelhos eletrônicos, radiação, poluição, agrotóxicos e camada de ozônio encontram-se contemplados, indicando um novo momento no currículo no Brasil, não só de química, mas de ciências da natureza como um todo.

\section{CONSIDERAÇÕES FINAIS}

De modo geral, observou-se que a construção do currículo de química, através dos conteúdos listados dos LDs analisados percorre caminhos plurais, marcados por diferentes interesses associados a fatos do cotidiano, ora relacionado ao conteúdo em questão, ora sem correlação com o conteúdo.

Nota-se que os conteúdos a serem estudados pelo aluno, ao longo de sua vida escolar, apresentam-se pensados, em alguns momentos, de forma fragmentada, uma vez que é possível notar a repetição nítida, por exemplo, nos conteúdos do $9^{\circ}$ ano do Ensino Fundamental e $1^{\circ}$ do Ensino Médio com pouca ênfase no aprofundamento ou aumento da complexidade dos mesmos. Alguns temas são abordados com elementos inerentes ao currículo crítico transcendendo o simples contexto para atingir uma discussão política, econômica, social, 
cultural e ética, mas percebe-se que são incorporados (ainda) de forma muito lenta, devido às exigências dos documentos regulatórios e dos processos de escolha dos LDs através do PNLD, bem como às constantes mudanças globais, em termos de avanços tecnológicos e de informação, além de aspectos da universalização do ensino e das novas prerrogativas de um ensino de ciências e química voltado a todos os cidadãos que passaram a frequentar a escola. Esta condução lenta do processo de adequação (dos LDs aos documentos e previsões normativas) pode ser vista quando se compara os conteúdos do LD da década de 1970, com os atuais, sendo possível notar diversas semelhanças - não obstante décadas transcorridas.

Embora a quase totalidade dos LDs analisados tenha feito parte do PNLD, a adequação destes aos conteúdos preconizados pelos documentos orientadores do ensino no Brasil pôde ser aqui evidenciada, de forma, não raramente, tímida. No entanto, corroborando a afirmação retro de que o cenário político, econômico e social é orientador dos rumos do currículo - inclusive de ciências e química - aguardam-se as modificações que certamente serão produzidas no novo cenário (em esboço) no Governo Brasileiro atual, especialmente no que tange à entrada em vigor da BNCC. Em relação a esta, alguns anos serão necessários à adequação dos LDs e demais documentos orientadores do ensino no país.

De um modo geral, pode-se concluir que o currículo é influenciado pelos acontecimentos na sociedade como um todo, nem sempre refletindo apenas o contexto do país, mas seguindo - tal qual nos séculos anteriores - as tendências globais, como é possível evidenciar em relação aos temas aquecimento global, lixo, reciclagem, em síntese, preocupação com o meio ambiente, etc. No entanto, os reflexos no currículo brasileiro demoram consideravelmente a ocorrer, sendo esperado, por exemplo, que modificações referentes às descobertas mais recentes, como novos materiais, elementos químicos, etc. ocupem páginas de nossos LDs em dez (ou mais) anos.

\section{REFERÊNCIAS}

ALBUQUERQUE, F. F. L. Que sabemos sobre o livro didático. Revista Brasileira de Estudos Pedagógicos, Brasília, v. 61, n. 138, p. 218-223, jun. 1976.

SILVA, F. A.; ALVES, J. Q.; ANDRADE, J. J. Propostas curriculares e práticas docentes: o que pensam/dizem os professores? Revista Brasileira de Pesquisa em Educação em

Ciências, v. 16, n. 1, p. 149-165, 2016. 
AMARAL, I. A. Os fundamentos do ensino de ciências e o livro didático. In:

FRACALANZA, H.; MEGID NETO, J. (Orgs.), O Livro Didático de Ciências no Brasil. Campinas, SP: Komedi, 2006. p. 83-123.

BRASIL. Constituição da República Federativa do Brasil. Brasília, DF, 1988. Disponível em: http://www.planalto.gov.br/ccivil 03/constituicao/constitui\%C3\%A7ao.htm.

BRASIL. Parâmetros Curriculares Nacionais. Brasília, DF, 1997. Disponível em: http://portal.mec.gov.br/seb/arquivos/pdf/livro04.pdf

BRASIL. Parâmetros Curriculares Nacionais para o Ensino Médio: Parte III. Brasília, DF, 2000. Disponível em: http://portal.mec.gov.br/seb/arquivos/pdf/14_24.pdf

BRASIL. PCN+ Ensino Médio: Orientações Educacionais complementares aos Parâmetros Curriculares Nacionais - Ciências da Natureza, Matemática e suas Tecnologias. Brasília: DF, 2000. Disponível em: http://portal.mec.gov.br/seb/arquivos/pdf/CienciasNatureza.pdf

BRASIL. Base Nacional Comum Curricular: Educação é a base. Brasília, DF, 2017. Disponível em: http://basenacionalcomum.mec.gov.br/wpcontent/uploads/2018/06/BNCC_EnsinoMedio_embaixa_site_110518.pdf

CALEGARI, R. P. Os 210 anos da Pedagogia Jesuíta no Brasil. In: Anais do Seminário Internacional de Educação Superior. Sorocaba, SP, 2014. p. 1-10. Disponível em: http://uniso.br/publicacoes/anais_eletronicos/2014/5_es_memoria/03.pdf

CAREGNATO, R. C. A.; MUTTI, R. Pesquisa qualitativa: análise de discurso vs análise de conteúdo. Texto \& Contexto Enfermagem, v. 15, n. 4, p. 679-684, 2006. Disponível em: http://www.scielo.br/pdf/tce/v15n4/v15n4a17.pdf

CARVALHO, L. R. A. A educação brasileira e a sua periodização. Revista Brasileira de História da Educação, v. 1, n. 2, p. 137-152, 2001. Disponível em: http://periodicos.uem.br/ojs/index.php/rbhe/article/view/38745/20275

ECHEVERRIA, A. R.; MELLO, I. C.; GAUCHE, R. Livro didático: análise e utilização no ensino de química. In: SANTOS, W. L. P.; MALDANER, O. A. (Orgs.), Ensino de Química em foco. Ijuí, RS: Unijuí, 2010. p. 263-286.

FRACALANZA, H. O ensino de ciências no Brasil. In: FRACALANZA, H.; MEGID NETO, J. (Orgs.), O Livro Didático de Ciências no Brasil. Campinas, SP: Komedi, 2006. p. 126152.

FRACALANZA, H. O livro didático de ciências: novas ou velhas perspectivas. In: FRACALANZA, H.; MEGID NETO, J. (Orgs.), O Livro Didático de Ciências no Brasil. Campinas, SP: Komedi, 2006. p. 174-195.

FRACALANZA, H.; MEGID NETO, J. O livro didático de ciências: problemas e soluções. In: FRACALANZA, H.; MEGID NETO, J. (Orgs.), O Livro Didático de Ciências no Brasil. Campinas, SP: Komedi, 2006. p. 153-169.

GOODSON, I. F. Currículo: teoria e história. Petrópolis, RJ: Vozes, 1995.

HOFLING, E. M. Notas para a discussão quanto à implementação de programas de governo: Em foco o Programa Nacional do Livro Didático. Revista Educação \& Sociedade, v. 21, n. 70, p. 159-170, 2000. Disponível em: http://dx.doi.org/10.1590/S0101-73302000000100009 
KRASILCHIK, M. Reformas e realidade: o caso do ensino das ciências. São Paulo em Perspectiva, v. 14, n. 1, p. 85-93, 2000.

LEÃO, F. B. F.; MEGID NETO, J. Avaliações oficiais sobre o livro didático de ciências. In: FRACALANZA, H.; MEGID NETO, J. (Orgs.), O Livro Didático de Ciências no Brasil. Campinas, SP: Komedi, 2006. p. 35-80.

Lei n. 15, de 15 de outubro de 1827. Dispõe sobre a criação de escolas no império. Rio de Janeiro, RJ, 1827. Disponível em: http://www.planalto.gov.br/ccivil_03/leis/lim/LIM-15-101827.htm.

Lei n. 9.394, de 20 de dezembro de 1996. Dispõe sobre as diretrizes e bases da educação. Brasília, DF, 1996. Disponível em: http://www.planalto.gov.br/ccivil 03/LEIS/19394.htm. Lei $n^{0} 13.005$, de 25 de junho de 2014. Dispõe sobre o plano nacional de educação. Brasília, DF, 2014. Disponível em: http://www.planalto.gov.br/ccivil_03/ato20112014/2014/lei/113005.htm.

Lei no 13.415 de 16 de fevereiro de 2017. Dispõe sobre mudanças no ensino médio. Brasília, DF, 2017. Disponível em: http://www.planalto.gov.br/ccivil_03/_ato20152018/2017/Lei/L13415.htm.

LIMA, M. E. C. C.; SILVA, N. S. A química no ensino fundamental: uma proposta em ação. In: ZANON, L. B.; MALDANER, O. A. (Orgs.), Fundamentos e propostas de ensino de química para a educação básica no Brasil. Ijuí, RS: Unijuí, 2007. p. 89-107.

LOPES, A. C. Currículo e Epistemologia. Ijuí, RS: Unijuí, 2007.

MACHADO, A. H.; MORTIMER, E. F. Química para o ensino médio: fundamentos, pressupostos e o fazer cotidiano. In: ZANON, L. B.; MALDANER, O. A. (Orgs.),

Fundamentos e propostas de ensino de química para a educação básica no Brasil. Ijuí, RS: Unijuí, 2007. p. 21-41.

MARCÍLIO, M. L. História da Escola em São Paulo e no Brasil. São Paulo, SP: Imprensa Oficial, 2005.

MEGID NETO, J.; FRACALANZA, H. O livro didático de ciências: Problemas e soluções.

Ciência \& Educação, v. 9, n. 2, p. 147-157, 2003. Disponível em:

http://dx.doi.org/10.1590/S1516-73132003000200001.

MENEZES, M. G.; SANTIAGO, M. E. Contribuição do pensamento de Paulo Freire para o paradigma curricular crítico-emancipatório. Pro-Posições [online], v. 25, n.3, p.45-62, 2014. Disponível em: http://dx.doi.org/10.1590/0103-7307201407503.

MORI, R. C.; CURVELO, A. A. S. O que sabemos sobre os primeiros livros didáticos brasileiros para o ensino de Química. Química Nova, v. 37, n. 5, p. 919-926, 2014. https://dx.doi.org/10.5935/0100-4042.20140148

RIBEIRO, M. L. S. História da Educação Brasileira: a organização escolar. 18a ed. Campinas, SP: Autores Associados, 2003

RODRIGUES, L. S. As pesquisas sobre Livros Didáticos: Uma análise de periódicos da área de Educação em Ciências. In: X ANPED SUL, p. 1-19. Florianópolis, Santa Catarina/Brasil, 2014. Disponível em: http://xanpedsul.faed.udesc.br/arq_pdf/2101-0.pdf.

SANTOS, W. L. P. Contextualização no ensino de ciências por meio de temas CTS em uma perspectiva crítica. Ciência \& Ensino, n. 1[especial], p. 1-12, 2007. Disponível em: http://www.cienciamao.usp.br/tudo/exibir.php?midia=rcen\&cod=_contextualizacaonoensino. 
SANTOS, W. L. P.; SCHNETZLER, R. P. Função social: o que significa ensino de química para formar o cidadão? Química Nova na Escola, n. 4, p. 28-34, nov. 1996. Disponível em: http://qnesc.sbq.org.br/online/qnesc04/pesquisa.pdf

SAVIANI, D. História das ideias pedagógicas no Brasil. Campinas, SP: Autores Associados, 2007.

SCHNETZLER, R. P. Apontamentos sobre a história de ensino de química no Brasil. In: SANTOS, W. L. P.; MALDANER, O. A. (Orgs.), Ensino de química em foco. Ijuí, RS: Unijuí, 2010. p. 51-75.

SCHNETZLER, R. P. Um estudo sobre o tratamento do conhecimento químico em livros didáticos brasileiros dirigidos ao ensino secundário de química de 1875 a 1978. Química Nova, v. 4, n. 1, p. 6-15, 1981.

SILVA, A. H.; GOMES, L. C. A teoria de aprendizagem de Bruner e o ensino de ciências. Arquivos do Mudi, v. 26, n. 3, p. 13-25, 2017.

SILVA, T. T. Documentos de identidade: uma introdução às teorias do currículo. $2 \mathrm{a}$ ed. Belo Horizonte, MG: Autêntica, 2007.

ZANON, L. B.; PALHARINI, E. M. A Química no Ensino Fundamental de Ciências. Química Nova na Escola, São Paulo, n. 2, p. 15-18, nov. 1995.

ZOTTI, S. A. O ensino secundário no império brasileiro: considerações sobre a função social e o currículo do colégio D. Pedro II. Revista HISTEDBR On-line, n. 18, p. 29-44, 2005.

Disponível em: http://www.histedbr.fe.unicamp.br/revista/revis/revis18/art04_18.pdf.

\begin{tabular}{|l|l|}
\hline & Recebido em: 28 Fev. 2019 \\
\hline & Aprovado em: 18 Abr. 2019 \\
\hline
\end{tabular}

